\title{
Focus on long-term cognitive, psychological and physical impairments after critical illness
}

\author{
Thomas Bein ${ }^{1 *}(0)$ O. Joseph Bienvenu ${ }^{2}$ and Ramona O. Hopkins $3,4,5$
}

๑ 2019 Springer-Verlag GmbH Germany, part of Springer Nature

The decades from 1990 to 2010 saw a clinical and research focus on technical, pharmaceutical, and scientific advances in intensive care medicine, and the key question was "Will my patient survive or die?" More recent decades have focused on "How will my patient survive?", and in consequence, many studies are investigating patient-centered outcomes after critical illness [1]. The adverse long-term outcomes are collectively known as post intensive care syndrome (PICS). In general, PICS refers to long-term physical, neurocognitive and psychiatric sequelae that adversely affect health-related quality of life (HRQL) and daily functioning [2]. The Center for Disease Control defines HRQL as 'an individual's (or a group's) perceived physical and mental health over time. HRQL is a multidimensional construct which can be individual, intimate and complex, and it may be nearly impossible to 'press' such a construct into a score or quantitative summary. Nevertheless, some important recent investigations have highlighted specific aspects of long-term outcome and HRQL after critical illness, and they have provided approaches for prevention or attenuation of long-term morbidities.

A recent review of patients who survive acute respiratory distress syndrome (ARDS) found a substantial reduction in HRQL (physical activity, depression, anxiety, post-traumatic stress disorder [PTSD], and vitality domains [3]); however, the reduction in HRQL was similar to that of patients surviving other critical illnesses. In a prospective 5-year longitudinal study in 196 ARDS survivors [4] 38\% of patients had prolonged symptoms of anxiety, 32\% depression and 23\% PTSD. Further, worse

\footnotetext{
*Correspondence: thomas.bein@klinik.uni-regensburg.de

1 Department of Anesthesia, Regensburg University Hospital, 93042 Regensburg, Germany

Full author information is available at the end of the article
}

pre-ARDS mental health was strongly associated with long-term psychiatric symptoms after ICU discharge. In consequence, a careful anamnesis of psychiatric history in ARDS patients may help identify patients at highest risk for prolonged psychiatric morbidity [5].

Comparable to ARDS, sepsis is a potentially life-threatening disease that challenges staff and is associated with high mortality and morbidity. Little data exist on HRQL in sepsis survivors. A recent study found significantly lower HRQL in physical and social functioning, role physical, general health, and vitality domains compared to United States population data [6]. Thompson et al. compared long-term outcomes of patients who survived sepsis with the outcome of non-septic critical illness survivors [7]. There were no significant differences in the number of reported problems with mobility (sepsis $37.8 \%$ vs. non-sepsis $38.7 \%, p=0.86$ ), ability to perform self-care $(24.7 \%$ vs. $26.0 \%, p=0.44)$, pain/discomfort $(42.4 \%$ vs. $41.6 \%, p=0.54)$ or anxiety/depression $(36.9 \%$ vs. $37.7 \%, p=0.68$ ) at 6 months. In a qualitative study of HRQL, the sepsis survivors reported difficulties with psychological disorders, fatigue, physical impairment, coping with daily life, ability to walk, return to normal living, cognitive impairments, self-perception, and control over life [8].

We have limited information regarding risk factors for development of PICS and their relationship with HRQL in surviving ICU-patients. In a large French and European Outcome Registry in ICUs (FROG-ICUstudy) Bastian et al. [9] investigated the influence of the socioeconomic status and deprivation on HRQL, depression, anxiety and PTSD in 1834 surviving ICU patients. Up to $31.6 \%$ of survivors presented symptoms of PTSD and $31.5 \%$ of survivors reported clinically meaningful symptoms of anxiety or depression. Quality-of-life scores were lower in the ICU survivors compared to the general French population. Patients who had lower

\section{6 Springer}


socioeconomic status scored significantly lower on the Short Form-36 physical component scale (median 47.5, IQR 30-68.8) compared to patients without social deprivation [54.4, IQR (35-78.8); $p=0.010$ ] and $32 \%$ in the non-deprived group and 15\% in the deprived group had significant symptoms of PTSD. These findings suggest that increased awareness is warranted in terms of recognition of impaired physical activities in individuals with low socioeconomic status. Interventions to prevent or ameliorate adverse psychological outcomes (depression, anxiety, and PTSD) and improve quality of life are also needed.

Most critical illnesses result in inflammation which, per se, may contribute to neurologic complications. Hughes et al. investigated the relationships between a marker of the blood-brain barrier integrity (S100B), a marker of neuronal (Ubiquitin C-terminal hydrolase L1 [UCHL1]) and of endothelial (E-selectin) injury and long-term cognitive impairment, and the impact of inflammation on this relationship [10]. In 419 survivors of critical illness both S100B and E-selectin were associated with global cognitive impairment at 3 and 6 months after discharge, whereas for UCHL1 this association was only seen at 3 months. Some of these associations were modified by inflammation. These findings suggest that plasma biomarkers measured early in the ICU are associated with neuronal damage. This study also highlights a potential pathophysiologic relationship between inflammation and development of cognitive impairments.

The ability to return to work is a paramount contributor to quality of life, and many people experience 'work' not only as a necessity but as an important factor in self-realization and satisfaction. The inability to return to work is common after critical illness, and PICS morbidities are important impediments to return to work. A recent Danish register-based cohort study [11] found among 5762 ICU survivors that $68 \%$ had returned to work within 2 years of hospital discharge. Mechanical ventilation (HR 0.70, 95\% CI 0.65-0.77) as well as longer ICU length of stay were significantly associated with a reduced chance to return to work. Furthermore, sick leave and receipt of disability pension were common in all surviving ICU patients. Similarly, a multicenter study in 923 ARDS survivors [12] found that $44 \%$ of patients employed prior to their critical illness were jobless at 12 months follow-up. After accounting for death and retirement only half returned to work by 12 months. Of the ARDS survivors $71 \%$ had lost earnings with a mean of $\$ 26,949 \pm \$ 22,447$. Further, being non-white, having a longer hospital length of stay and older age were associated with joblessness. A study by Norman et al. [13] assessed the association between employment at 3 and 12 months after critical illness and global cognitive

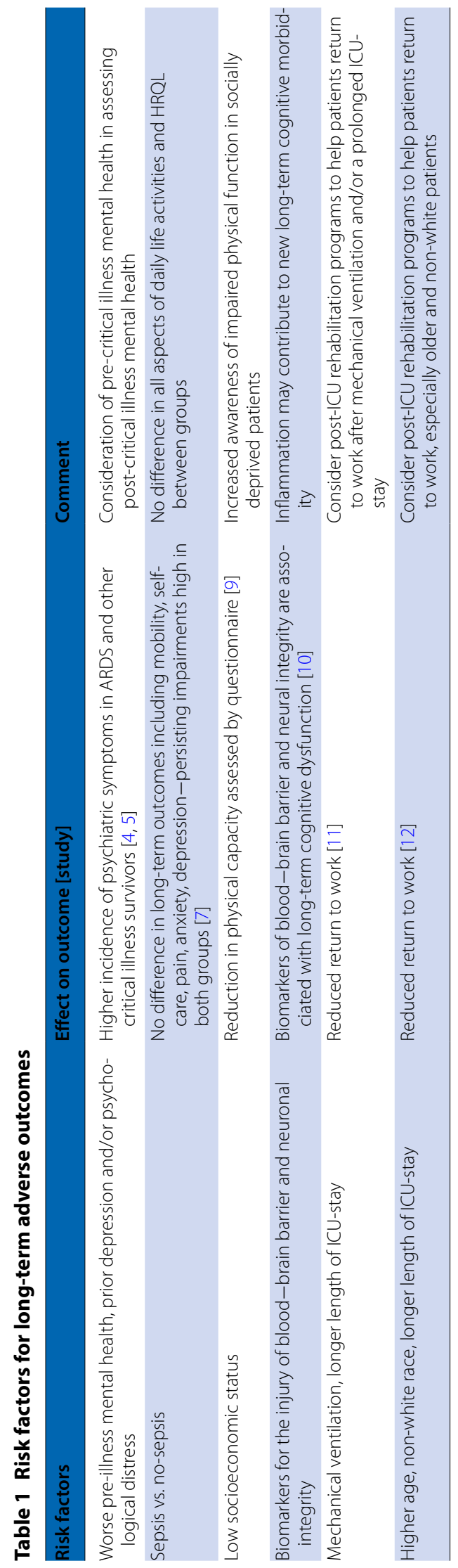


function. At 3 (62\%) and 12 months (49\%) follow-up a decrease in employment was observed and 47 and $49 \%$ of previously employed survivors were jobless. Cognitive impairments at 12 months were associated with unemployment.

In conclusion, important recent investigations have extended our knowledge regarding long-term outcomes and HRQL after critical illness (Table 1). These studies identified several risk factors (e.g., socioeconomic status, pre-ICU health and employment, markers of brain injury, intensity of organ support, and length of ICU-stay) for development of cognitive, psychological, and physical sequelae and reduced HRQL after ARDS or other critical illness. The development of more precise instruments to predict neuropsychological or physical morbidity is needed [14] and, in the future, studies surviving patient's opinions regarding the decisions made during acute treatment should be integrated. In a prospective, longitudinal study conducted in 315 patients being weaned from prolonged ventilation at a long-term acute-care hospital [15] $84.7 \%$ of survivors indicated willingness to undergo mechanical ventilation again. Clinical investigations of the effects of various interventions, including new technologies (e.g., early neurocognitive rehabilitation software [16]) are urgently required to improve long-term outcome after critical illness.

\begin{abstract}
Author details
1 Department of Anesthesia, Regensburg University Hospital, 93042 Regensburg, Germany. ${ }^{2}$ Department of Psychiatry and Behavioral Sciences, Outcomes After Critical IIIness and Surgery (OACIS) Group, Johns Hopkins School of Medicine, Baltimore, MD, USA. ${ }^{3}$ Neuroscience Center and Psychology Department, Brigham Young University, Provo, UT, USA. ${ }^{4}$ Pulmonary and Critical Care Medicine, Intermountain Medical Center, Murray, UT, USA. ${ }^{5}$ Center for Humanizing Critical Care, Intermountain Health Care, Murray, UT, USA.
\end{abstract}

\section{Compliance with ethical standards}

\section{Conflicts of interest}

All authors declare no conflicts of interest.

\section{Publisher's Note}

Springer Nature remains neutral with regard to jurisdictional claims in published maps and institutional affiliations.

Received: 27 June 2019 Accepted: 27 July 2019

Published online: 5 August 2019

\section{References}

1. Iwashyna TJ (2010) Survivorship will be the defining challenge of critical care in the 21st century. Ann Intern Med 153:204-205
2. Brown SM, Bose S, Banner-Goodspeed V, Beesley S, Dinglas VD, Hopkins RO, Jackson JC, Mir-Kasimov M, Needham DM, Sevin CM, Addressing Post Intensive Care Syndrome 01 (APICS-01) study team (2019) Approaches to addressing post-intensive care syndrome among intensive care unit (ICU) survivors: a narrative review. Ann Am Thorac Soc. https://doi.org/10.1513/ annalsats.201812-913fr

3. Bein T, Weber-Carstens S, Apfelbacher C (2018) Long-term outcome after the acute respiratory distress syndrome: different from general critical illness? Curr Opin Crit Care 24:35-40

4. Bienvenu OJ, Friedman LA, Colantuoni E, Dinglas VD, Sepulveda KA, Mendez-Tellez P, Shanholz C, Pronovost PJ, Needham DM (2018) Psychiatric symptoms after acute respiratory distress syndrome: a 5-year longitudinal study. Intensive Care Med 44:38-47

5. Nikayin S, Rabiee A, Hashem MD, Huang M, Bienvenu OJ, Turnbull AE, Needham DM (2016) Anxiety symptoms in survivors of critical illness: a systematic review and meta-analysis. Gen Hosp Psychiatry 43:23-29

6. Heyland DK, Hopman W, Coo H, Tranmer J, McColl MA (2000) Longterm health-related quality of life in survivors of sepsis. Short Form 36: a valid and reliable measure of health-related quality of life. Crit Care Med 28:3599-3605

7. Thompson K, Taylor C, Jan S, Li Q, Hammond N, Myburgh J, Saxena M, Venkatesh B, Finfer S (2018) Health-related outcomes of critically ill patients with and without sepsis. Intensive Care Med 44:1249-1257

8. König C, Matt B, Kortgen A, Turnbull AE, Hartog CS (2019) What matters most to sepsis survivors: a qualitative analysis to identify specific healthrelated quality of life domains. Qual Life Res 28:637-647

9. Bastian K, Hollinger A, Mebazaa A, Azoulay E, Féliot E, Chevreul K, Fournier MC, Guidet B, Michel M, Montravers P, Pili-Floury S, Sonneville R, Siegemund M, Gayat E, FROG-ICU Study Investigators (2018) Association of social deprivation with 1-year outcome of ICU survivors: results from the FROG-ICU study. Intensive Care Med 44:2025-2037

10. Hughes CG, Patel MB, Brummel NE, Thompson JL, McNeil JB, Pandharipande PP, Jackson JC, Chandrasekhar R, Ware LB, Ely EW, Girard TD (2018) Relationships between markers of neurologic and endothelial injury during critical illness and long-term cognitive impairment and disability. Intensive Care Med 44:345-355

11. Riddersholm S, Christensen S, Kragholm K, Christiansen CF, Rasmussen BS (2018) Organ support therapy in the intensive care unit and return to work: a nationwide, register-based cohort study. Intensive Care Med 44:418-427

12. Kamdar BB, Huang M, Dinglas VD, Colantuoni E, von Wachter TM, Hopkins $\mathrm{RO}$, Needham DM, National heart, lung, and blood institute acute respiratory distress syndrome network (2017) Joblessness and lost earnings after acute respiratory distress syndrome in a 1-year national multicenter study. Am J Respir Crit Care Med 196:1012-1020

13. Norman BC, Jackson JC, Graves JA, Girard TD, Pandharipande PP, Brummel NE, Wang L, Thompson JL, Chandrasekhar R, Ely EW (2016) Employment outcomes after critical illness: an analysis of the bringing to light the risk factors and incidence of neuropsychological dysfunction in ICU survivors cohort. Crit Care Med 44:2003-2009

14. Milton A, Schandl A, Soliman IW, Meijers K, van den Boogaard M, Larsson IM, Brorsson C, Östberg U, Oxenbøll-Collet M, Savilampi J, Paskins S, Bottai M, Sackey PV (2018) Development of an ICU discharge instrument predicting psychological morbidity: a multinational study. Intensive Care Med 44:2038-2047

15. Jubran A, Grant BJB, Duffner LA, Collins EG, Lanuza DM, Hoffman LA, Tobin MJ (2019) Long-term outcome after prolonged mechanical ventilation. A long-term acute-care hospital study. Am J Respir Crit Care Med 199:1508-1516

16. Turon M, Fernandez-Gonzalo S, Jodar M, Gomà G, Montanya J, Hernando D, Bailón R, de Haro C, Gomez-Simon V, Lopez-Aguilar J, Magrans R, Martinez-Perez M, Oliva JC, Blanch L (2017) Feasibility and safety of virtual-reality-based early neurocognitive stimulation in critically ill patients. Ann Intensive Care 7:81 